$$
\begin{aligned}
& \text { THE PURPOSE } \\
& \text { OF EDUCATION } \\
& \text { ST GEORGE LANE FOX PITT }
\end{aligned}
$$

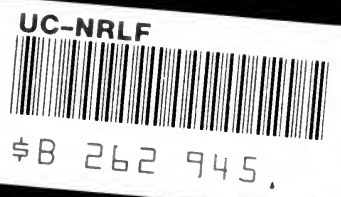



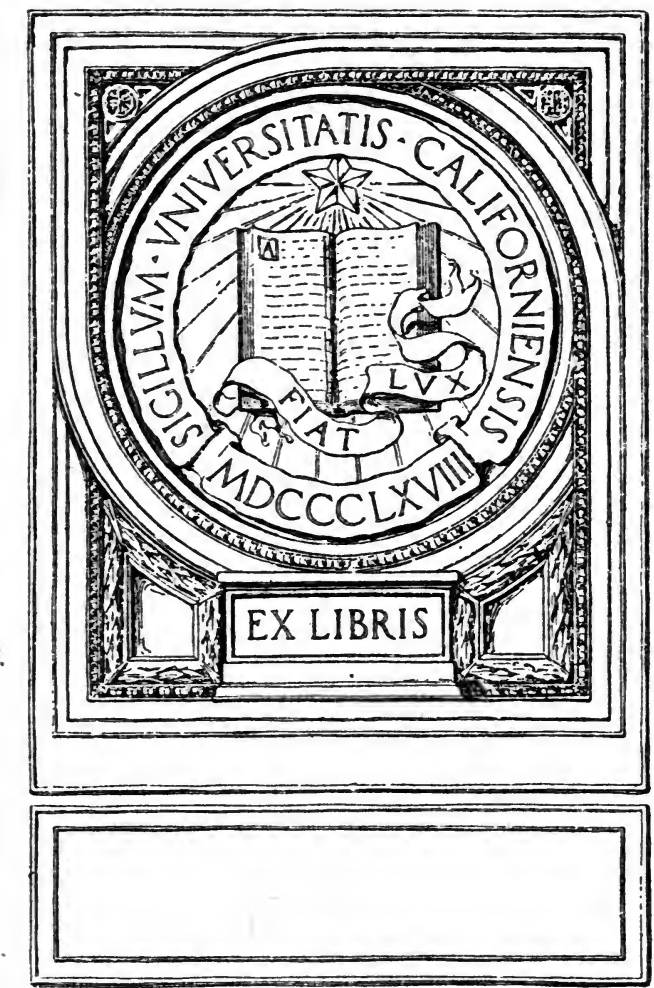
Digitized by the Internet Archive in 2007 with funding from Microsoft Corporation 



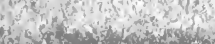

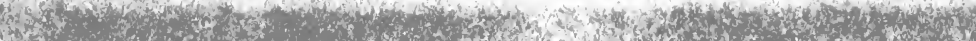

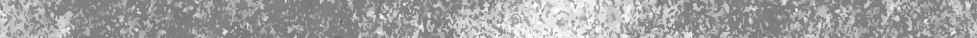

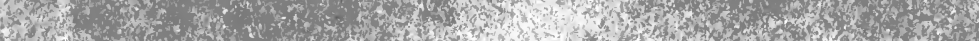

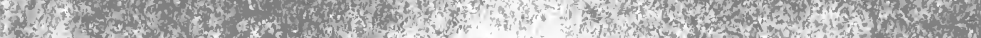

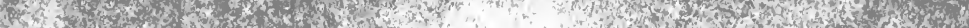
T.

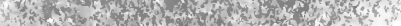
is.

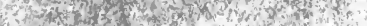
6. Ning

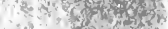
thin

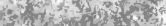
int

som (x) $10+5$

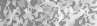
20.5. 90 $143 \times 10$

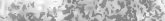

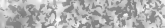
A.

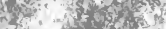

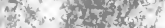
4. 10 -

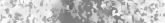
Wit? ind

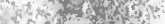

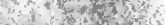

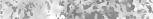
(6) 35 , Not a c yos? tiol ins 2.

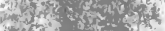
Fis

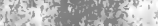
H. 92.40. Whe 51,25 whe - v the

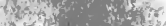

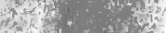

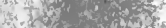
W. 35 2

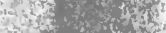

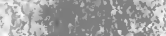
sot a) fis not $x^{2}$

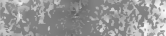
2. $3 x$ $7 b^{2}=\frac{x}{2}$

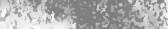

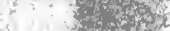
3.teronts cosion

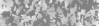

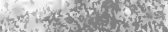

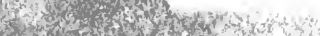

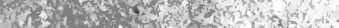

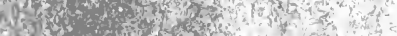
math

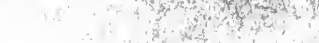
7.

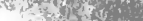
ind $x$ ing क. तो instion is $x_{1}$ T. atis 1 350 . Heto itomests Finotis. instio tor 5 a sind

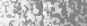
efest Nat $x$ oriter ionQ18 1 is Whentio Git

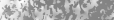
28 ris are it $3 \times 2$. ind tort N3t? the ind to to (2) amertis

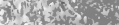
is $x$, w 2 B.

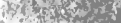

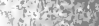
notsyon and

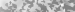
mits incosom (x) A

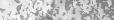
3. $\mathrm{N}^{2}=150$ 7. ind 13. 0 dis nive 0 incolos ix $3 x+5$ is $40,5 \mathrm{~s}$ )otit 36

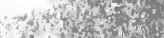

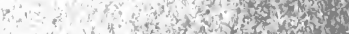
$x=350$

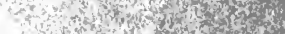

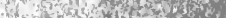

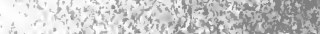

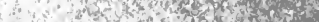

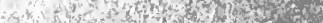

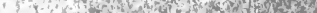

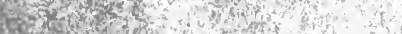

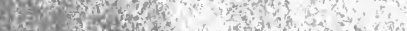

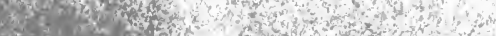
(10)

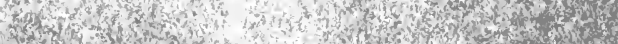

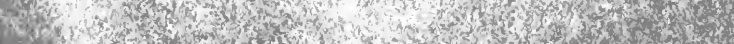

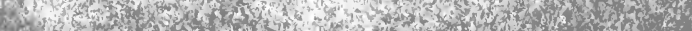

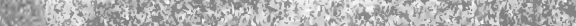





\section{THE PURPOSE OF EDUCATION}




\section{CAMBRIDGE UNIVERSITY PRESS}

Zllondon: FETTER LANE, E.C.

C. F. ClAY, MANAGER

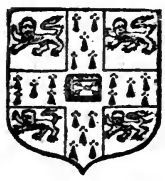

CEinburgf: IOO, PRINCES STREET Berlin: A. ASHER AND CO.

leipzig: F. A. BROCKHAUS

fitw gork: G. P. PUTNAM'S SONS

3omban and Calcutta: MACMILLAN AND CO., LTD.

Toronto: J. M. DENT AND SONS, LTD.

Tokngo: THE MARUZEN-KABUSHIKI-KAISHA 


\section{THE PURPOSE OF}

\section{EDUCATION}

An Examination of the Education Problem in the Light of Recent Psychological Research

by

ST GEORGE LANE FOX PITT

Member of the Permanent Executive Council

of the

International Moral Education Congress

and

Member of the Council of the Society for Psychical Research

Cambridge :

at the University Press

I 9 I 3 


\section{Cambrioge:}

PRINTED BY JOHN CLAY, M.A.

AT THE UNIVERSITY PRESS 


\section{PREFACE}

F XPERIMENTAL psychology has made considerable progress in recent years. Fresh knowledge as to the facts relating to the working of the human mind has been discovered; and a new terminology has been evolved.

It is the object of the present work to apply this knowledge to the elucidation of educational problems, in the hopes that some of the confusions and difficulties which prevail, both in the public mind and that of experts, may, to some extent at any rate, be cleared up. Much of the ground covered will naturally be familiar to teachers and students of the subject; but the explanations offered of the psychical processes involved in the art of pedagogy may be helpful in the endeavour of reformers to improve and systematise the somewhat chaotic methods at present in vogue.

The chief difficulty encountered in all attempts at the effective presentation of un- 
familiar ideas, consists in the discovery and adaptation of a suitable terminology. To some extent, no doubt, this difficulty can be met by the practice of paraphrasing, but the employment of a precise and systematic nomenclature is also important. It is not improbable that many readers may be irritated and even put off by the frequent use in these pages of the word "complex" for the purpose of indicating those egocentric phases of mind, which are more usually, if more vaguely, denominated by the words memory, mood, or motive. The term "complex" is now, however, current and accepted in all the more important works, recently issued, which bear upon medical, or abnormal psychology and kindred subjects. The study of abnormal psychology has helped to reveal the rationale and modus operandi of thought and feeling, and the term "complex" has been used to designate an undoubted discovery, arising out of this study, as to the mode in which specific psycho-physical processes occur and function, not only in morbid conditions of mind and body, but also in normal life. The author hopes, therefore, that its use may be admitted here as being neither arbitrary, nor pedantic. 
Great stress has been laid on the educational value of high ideals : upon their inculcation and growth. With this end in view an attempt is made to indicate certain important distinctions and discriminations, which are essential preliminaries to that true unification of thought lying at the root of universal beliefs. It is easy enough to profess admiration for the ideal human qualities : charity, tolerance, impartiality, honesty and the like ; but it is very difficult to understand why, in practice, these ideals should so often be disregarded, not to say systematically ignored. The use of certain familiar words is often supposed to supply an "explanation." "Mystery," "sin," "selfishness," "disobedience," "malice," "ignorance" are all made to serve their turn. Words, however, are not explanations. Explanations are the product of experience and meditation through which there is an awakening of the higher faculties of insight and understanding.

It is, of course, generally recognised that certain familiar expressions convey varying implications according to the context in which they occur ; and that this represents a common linguistic difficulty. The inconvenience of this 
ambiguity, however, becomes a serious trouble when, as sometimes happens, the different meanings attached to the same word are diametrically opposed. Thus "charity" suggests both "self-denial" and "self-gratification" in varying degrees dependent on our preconceptions as to the theory of "self." So it is with "tolerance," "impartiality" and "honesty."

In the contemplation of the huge extent of human suffering some are apt to grow impatient and to demand the discovery of an immediate and final remedy! In this search the trend of thought seems to oscillate between one extreme and another. At one time the prevailing view is directed towards making exaggerated claims for the importance of the inner life, and at other times it is directed towards an exaggeration of the importance of "environment." It is one of the main objects of these pages to indicate the middle path, which avoids these two extremes.

St G. L. F. P.

Traveluers' Clob,

Pall Mall,

LoNDoN.

19 October, 1913 


\section{TABLE OF CONTENTS}

CHAP.

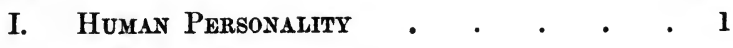

II. Emotton AND Instinct • . . . $\quad$. 25

III. Character versus Reputation • • $\quad 35$

IV. Incentives to Effort. Economics . 40

V. Specialisation $\quad$ - $\quad$ - $\quad$ - $\quad$ • $\quad 55$

VI. Multiplex Environment • • • • 61

VII. Religions, Ideals, the Twice-Born $\quad$ - 71 



\section{ERRATA}

p. 8 , line 2 , for nobility read mobility

p. 62 , line 4 also in footnote and p. 63 , line 2 , for physic read psychic 



\section{CHAPTER I}

\section{HUMAN PERSONALITY}

IT is a commonplace saying that ignorance and prejudice die hard. It is not, however, so easily perceived that the death of this ignorance and prejudice almost invariably gives rise to their re-birth in new forms, which are but a shade nearer to the expression of the truth than the old forms they have replaced. So also is there rebirth of universal truths, those grand synthetic generalizations, which obtain with more or less persistence among all peoples and in all times. With truth there can be nothing fundamentally new, though its re-expression in terms of current experience may come with all the force and attractiveness of novelty. But the barrier to its reception is just this ignorance and prejudice in the public mind, which it is the function of education to remove. Thus we find many words and phrases in the literature of all nations, bearing testimony to the contradictory nature of current beliefs and to the survival of old ones 
as to the meaning and import of the human personality. These beliefs fall in two main classes. According to the first and most numerous class, a "person" is the combination of a body, or physical organism with a permanent, more or less independent, soul-entity which animates it; and for such the great work of education consists in the harmonising of these two factors. The combination of body and soul, we are told, is something radically "evil." "Man is born in iniquity" and unless "saved," destined to perdition. With the second class of beliefs, the body is regarded as the real fact; the mind or character being considered as a quality or function of the physical organism, to be developed like a plant by contact with a suitable "environment." The propounders of this school of thought, while admitting as a rule, that much may be due to "heredity," insist, nevertheless, that the child is born fundamentally "good" and that the whole function of education is the skilful drawing out of its innate excellencies.

Now controversialists holding diametrically opposed doctrines, while vainly imagining that they have established the validity of their own thesis by an elaborate refutation of their 
opponents' point of view, are apt to exclaim "Both doctrines cannot be true." Well, perhaps not, but they can both be false, as indeed, almost invariably, they are.

Crude generalizations of either kind must as far as possible be discarded and their special nomenclature dispensed with, in order to clear the mind from misconception preparatory to giving serious and unbiassed consideration to the results and conclusions of modern psychology, on the point at issue.

This done, it may be stated positively, as a fact which has been clearly demonstrated, that the human personality under a thoroughgoing analysis, exhibits not a permanent and unalterably separate entity, but a vast combination or aggregation of variegated, fluctuating and loosely organised physical and psychic phases and potentialities, of which no more than a minute fragment makes its presence manifest to our ordinary, or "normal" waking consciousness. An illustration which has been found helpful, though the analogy must not be pressed too far, compares personality to an iceberg, ever changing in structure and substance, the great bulk of which is always invisible and submerged. 
As we approach to anything in the nature of fixity and permanence so we approach the impersonal.

We are all familiar with such phrases as being, or not being in a "mood" for anything : we speak of an attentive or a careless mood, a pleasant or a nasty mood, etc. We recognise the mental phenomena to which such phrases apply and as a rule we accept them as important factors in our lives, but we often misinterpret their meaning, or put them down as inexplicable.

Modern psychology explains the mystery by indicating the nature of the human mind. The study of modern psychology has shown that the mind is composed of a vast number and great variety of psycho-physical "complexes."

A "complex" may be defined as a group ${ }^{1}$ or system or "stream" of closely associated ideas, linked together in some experience, or succession of experiences, with corresponding emotions, perceptions, "memories," interests and range of

1 Neither "group," nor "system," nor "stream" are quite suitable terms to express that combination of ideas associated in a complex. "Vortex" might perhaps serve, though it would suggest analogy with fluid motion, which would have a misleading implication. "Dynamic System" would probably be the least objectionable. 
volitions; linked in such a manner as to be capable of so dominating some portion of the brain and nervous system as to generate a consciousness ${ }^{1}$, in conjunction with those ideas, of egoistic self-hood, however transitory and imperfect in its manifestation. The stimulation of one element of a complex will, generally speaking, excites activity in some or all the rest. Notwithstanding their apparent independence in functioning, all complexes are really allied to one another, more or less correlated and interdependent, but imperfectly co-ordinated in their manifestation. According to the rise and fall of different complexes in the field of vivid or focussed consciousness, so is one's change of mood.

The element of "emotion," sometimes called

1 The term "consciousness" implies transitory phases of mind, yielding conditions of awareness in great variety. These conditions usually involve the focussing of attention upon specific phenomena. The term "subconscious," as applied to mind, indicates such conditions of its development as are differentiated and, while not specifically focussed, are yet capable of being focussed. "Unconscious mind" is used to denote the potentiality of mind, i.e., mind, which is psychically undeveloped, individually undifferentiated and unprepared for focussing, as being outside human experience, in the sense of not having been assimilated with it. (See also Chapter VI.) 
"feeling," is of great importance in the functioning of a complex, as determining its relative capacity for persistence and isolated activity, and is dealt with more fully in a separate chapter; but it will suffice for a moment to say that the term is used here as an expression for the likes and dislikes, the pleasures and pains, as also such comparative notions as "preferences" and "choice of evils," which are characteristic of the bulk of our ordinary thoughts.

The discovery of psycho-physical complexes was foreshadowed, though somewhat vaguely, by Herbart, in his enunciation of what he terms "apperception masses."

The types of complexes are very various, but they may be classified roughly as belonging to three main orders :-

1. The minor variety, which is by far the most numerous kind and is, generally speaking, the more limited and transitory. They have their genesis in what are ordinarily called "events," or specific experiences; as for example a particular meal, a game, a privation, a lesson, an accident, a dispute, a punishment, an illness, a success or a failure. Even such a combination of events closely associated in our 
thoughts as constitute in themselves the separate and peculiar incidents of our lives in the nature of "personal experiences" great or small, form the basis of a minor complex.

2. The intermediate variety, comprising various intellectual concepts of a co-ordinating and synthetic nature. These complexes are in touch with certain specific "environments," both material and psychic, or what is often ignorantly styled "the real world." To this order, all viewed as transcending mere personal experiences, belong our notions of heat and cold, light, sound, weight, energy, space, number, and the qualities of matter; the ideas of life and death, and of hunger and thirst and food ; also the intellectual and moral qualities, such as kindness, cruelty, uprightness, diligence, cleverness and modesty. The element of personal experience, although an undoubted factor in the acquisition of such "concepts," is subordinated to the idea of universality. These complexes are in fact the equivalents of "concepts."

3. The great complex, i.e., the personality or character as a whole. This complex, rarely awakened as a vivid consciousness, is in harmony with the universal life. It has infinite potentialities. 
The strength and worth of our personality is determined by the quality, nobility and the co-ordination of the complexes out of which it is composed.

At any moment a specific complex, or several simultaneously (forming a "co-consciousness") may emerge into the field of normal, waking, focussed or vivid consciousness, while the rest, the vast majority, remain for the time being submerged ; exercising, no doubt, a vague kind of subtle influence in our thoughts and actions, though "automatically," unvolitionally, and so to speak, surreptitiously. There is an abundance of evidence, however, that while submerged in the subconscious strata of our existence, our dormant complexes do not persist in a static condition, but are subject to continual change. Nor do they remain isolated, for it has been demonstrated by means of hypnotic experiments ${ }^{1}$, that after successive emergence, they reappear modified by the assimilation of qualities and tendencies derived from allied complexes; even, be it said (though the fact is sometimes disputed), by psychic

1 See The Dissociation of a Personality by Morton Prince, M.D. (Longman \& Co.) 
communion with the subconscious elements of other personalities.

The same ideas, or to speak more correctly, similar concepts, may occur in various complexes, though allied to different feelings. Thus, for example, the idea food would present itself as attractive or the reverse according to the condition of the stomach and nervous system, the state of one's appetite, or dominant mood.

Let us now consider the origin and growth of complexes. They are the outcome of experience, both physical and psychical, though to what degree or in what manner respectively we shall not attempt to consider here. It will be enough at this juncture to point out that, although the distinction made between the physicalinstrument of thought and the psychical powers, is not to be regarded as amounting to independence, or absolute separateness of function, yet for the better understanding of educational processes, precise terminological definitions of these concepts, are of very great scientific importance.

It cannot be too strongly insisted upon that complexes are not static entities, but that they are each one ever changing and developing through their tendency to strengthen and perpetuate 
themselves by adaption to or assimilation with their respective "environments," or that aspect of real life to which they are complementary in the existing world "outside." In this struggle our various complexes compete, conflict and co-operate. In other words, each complex "ego" seeking to assimilate, or to destroy the "non-ego" gives rise to a change in both. It is this process which is most fundamental in the functioning of individualised life.

Now each fresh stimulative contact of the organism with some chosen, or "accidental" 1 environment makes an addition to, or some modification in, one or more of our complexes; so also when we "reflect," or "meditate," the mental operation involved implies some interaction between the complexes; while the relatively exclusive absorption, or concentration of consciousness, in one complex, such as is characteristic of intense emotion, great interest, idle brooding, or preoccupation of the mind with a "fixed idea," may tend to the strengthening

1 An environment is called "accidental" when its presence is unexpected, or unusual ; or where there is an absence of full awareness as to its relativity and proximity to the organism. (See Chapter VI.) 
of that complex and facilitate its repeated emergence in a more or less "dissociated" form. Assuming now that the development, or, as some would say, the awakening, of high character is the supreme aim of education, it must be obvious, from what has been said, that exclusive or too persistent concentration of consciousness in particular complexes is not advantageous, but the reverse. The right process for such an awakening is the harmonious development of various complexes in co-ordination with and in subordination to the intermediate complexes, in the first place, and then finally with the great complex, in so far as its awakening may be rendered possible. This later aspect of the problem is further considered in the chapter dealing with ideals.

The spontaneous tendency of complexes to assimilate with one another may be greatly facilitated by conscious effort, in conjunction with suitable externals in the shape of apparatus for illustration. In all individuals there are certain complexes which are, so to speak, near the surface, and thus more easily accessible. A skilled teacher will, therefore, by suggestion, endeavour to connect the subject he proposes 
to introduce to his pupils with some familiar group of ideas and interests. In this way the mind which is brought into action will be such an associated system of complexes manufactured as it were for the purpose of receiving instruction. And indeed it is generally admitted that the best form of "discipline" which can be employed, is the concentrated attention of the pupil; awakened by a genuine interest in the subject itself, rather than by a fear of the consequences of inattention and neglect.

One of the most important facts, which the investigations of modern psychology has revealed, is the extremely limited range of choice, in the determination of his conduct, which falls to the lot of the average child, or indeed, for that matter, of the average human being. Each complex, or group of complexes, has its own sphere of freedom of action and volition. In the actual practical life of an individual he becomes aware, though without full comprehension of its meaning, of a continual conflict of his numerous spheres of thought and action. True liberty is, therefore, not a mere condition of life which can be arbitrarily "given" or "taken away" by economic conditions, social 
conventions, or political institutions. It is a quality which springs from within and has to be gained by effort and perseverance; while that power, above all others, which can stimulate effort and make it effective in the direction of gaining mental freedom, is the assimilation of a right idea, to the extent of generating a true conviction, or what is termed a correct point of view. The test of right ideas and points of view is their power to harmonise and resolve the scattered contents of our manifold minor complexes in relation to one another, and to some of those complexes which belong to a higher order. The awakening of such true convictions is the real meaning of revelation. We may pass our lives in the repeated contemplation of various familiar phenomena, the connection between which is not suspected, when suddenly there arises a perception of their true relationship. What is this but a revelation?

Living in a damp cold climate we notice that grass will not grow well under a big tree. We also notice that on the north side of a wall our gardens will not flourish. From these and similar phenomena we infer that sunlight is needed for vegetation. Most of us feel brighter, 
more cheerful and in better health with much sunlight. The idea grows on us that sunlight is not only a good thing, but that the more we can get of it the better. We congratulate one another on the brightness and warmth of "fine" weather and deplore the coming of cold and damp. But let us visit a very dry hot climate, and the condition of things is reversed. We find that vegetation flourishes most luxuriantly under the shade of a cliff, and everything exposed to the open sunlight is dried up. People congratulate themselves on the presence of clouds and rain! Comparisons suggest themselves to our minds; and, by degrees to some, to others suddenly, there dawns upon our minds the ideas of moderation, proportion, balance. If now our complexes are mobile, that is to say if they are not charged too strongly with the tenacity of emotion, which tends to restrict and obstruct the reception of new ideas, this sense of moderation once gained in certain connections will rapidly spread to others.

The laws which govern the emergence of complexes are roughly speaking fourfold. Each complex has its own dynamic and inherent forces, which will, after a certain lapse of time 
and change of physical condition, bring it to the surface of its own accord, as for example in dreams. Then there is an emergence due to the exercise of the senses. Next there is an emergence possible in response to verbal suggestion. And finally there is the emergence due to our meditations. One might add, of course, a composite cause of emergence due to an indeterminate combination of any, or all of the above.

Space would not allow of a very full discussion of the experimental investigations which have led up to the generalizations and conclusions arrived at. But it may be stated that the author has himself made innumerable experiments on his own personality extending over some thirty years. With the help of anaesthetics and other expedients, he has done much to verify, correct and explore the work of other investigators. The serious student, however, may be referred to the Proceedings of the Society for Psychical Research, especially PartXLVI, which contains some very suggestive papers.

By way of illustrating what has been called a "dissociated" complex we may append the following extract from a very interesting paper, 
appearing in that volume, from the pen of $\mathrm{Dr}$ T. W. Mitchelt :-

"A complex formed in relation to some event accompanied by great emotion may become dissociated from the personal consciousness, so that all recollection of the event and of the feelings and actions connected with it becomes impossible. A complex so dissociated does not cease to be capable of functioning. For the time being it may become latent, but it may occasionally exhibit extremely independent activity. A case recorded by Professor Janet ${ }^{1}$ well illustrates the results of the functioning of such dissociated complexes.

"A young girl nursed her dying mother. The poor woman, who had reached the last stage of consumption, lived alone with her daughter in a poor garret. Death came slowly with suffocation, blood vomiting, and all its frightful procession of symptoms. The girl struggled hopelessly against the impossible. She watched her mother during sixty nights, working at her sewing-machine to earn a few pennies necessary to sustain their lives. After the mother's death she tried to revive the corpse, to call the breath back again;

1 The Major Symptoms of Hysteria, p. 29. 
then, as she put the limbs upright, the body fell to the floor, and it took infinite exertion to lift it up again into the bed. Some time after the funeral the young girl began to fall into somnambulic attacks in which she acted again all the events that took place at her mother's death, without forgetting the least detail.

"One of the characteristics of these recurrent psychomotor states or somnambulisms, as Janet calls them, is that they repeat themselves indefinitely. Not only are the attacks always (almost) exactly alike, repeating the same movements, expressions and words, but in the course of the same attack the same scene may be repeated many times (almost) exactly in the same way. The patient acts out some past experience as if in a dream, and during the attack the senses are shut to all impressions not connected with the dream. He perceives nothing except the idea he is possessed of, and he remembers nothing except that one idea. When the attack is over there is a return of all sensations, the lost memories of waking life are restored, and the events of the dream are forgotten. This loss of memory bears not only on the period of the somnambulism; it bears also on the event that 
has given birth to the somnambulism, on all the facts that are connected with it, and on the feelings that are related to it. Thus the young girl referred to forgot during her waking state all the events connected with her mother's illness and death. She was callous and insensible, and her filial love, the feeling of affection she had felt for her mother, seemed to have quite vanished."

This example shows how intense emotions may so develop and dissociate a complex as to throw the whole order and arrangement of our lives out of gear. Inasmuch, however, as the emotional element supplies, or rather concentrates, the driving power of our activities in the early stages of our mental growth, it is of great importance that we should make a special effort to understand its true meaning and function.

What it is exactly that people mean when they insist that a sound educational system should include the cultivation of the feelings as well as of the intellect, it would be difficult to say; for the growth of the feelings in one direction or another is inevitable. But vaguely no doubt, the suggestion is that the mere acquisition by children of mental and manual skill, 
added to a familiarity with certain intellectual concepts, without however an awakening of lofty aspirations, sympathy and kindness of heart, is morally speaking unprofitable, and may be indeed a curse rather than a blessing.

Now whatever importance we may attach to the influence of heredity, and this factor should by no means be disregarded, it is quite certain that an individual's tastes, that is to say, his likes and dislikes, his aims and preferences, are not fixed and unchangeable elements, but that they are qualities which can be cultivated, repressed and developed within a wide range of limits. It is, moreover, a well established fact that an ordinary individual's tastes are dependent on his beliefs, perceptions and habitual habits of thought. In other words, he likes what he believes in ; and also, in spite of his methods of "reasoning" (we might almost say in consequence of them) he is disposed to believe in the truth of what he likes. What we like and believe in, with some degree of persistence, is commonly called our "ideals."

We may remark in passing that this very generally recognised psychological fact, as to the interdependence of beliefs and wishes, is often 
dismissed with the phrase that "the wish is father to the thought," as a sufficient explanation. But it sometimes happens that the word "necessity" is used to express some attitudes of mind, attuned to strong and deeply-rooted wishes or cravings; especially where such feelings synchronise with the mental attitude of those with whom we have to deal. Thus we often speak of our "economic necessities" when we seek to give euphemistic expression to those settled mental habits, based upon desires and beliefs to which we have merely grown accustomed. The cravings which have engendered certain habits of thought are in this manner made to appear to be of such compelling force as to suggest the idea of something fixed and irrevocable, springing out of the very essence of our nature, determining our actions "against our will" and contrary to our "interests"! It will soon be made clear, however, that all our cravings are only relative and conditional, and that they should never, except by a misuse of terms, be spoken of as permanent or irresistible.

This brings us to the important and very difficult subject of instincts. The term "instinct" has been variously and inconsistently applied to 
a vast number of conflicting desires and proclivities, but generally to those more or less spontaneous tendencies, which prompt an organism's activities towards the advancement, or maintenance, of its "well-being." Instinct has been aptly defined as the inborn experience of the race to which the organism belongs. But what is race-experience? Clearly it must be the outcome of an aggregate individual experience-a synthetic boiling down of innumerable efforts, trials, successes and failures.

However vast and profound this experience may be, it cannot approach infallibility, as the circumstances in which the organism finds itself placed can be varied practically without limit.

In the early part of this chapter we have seen that an essential element in the composition of complexes is experience; and it is obvious that the nucleus of all individual experience must be race-experience. In other words, a complex has its primary basis in instinct. Inasmuch, however, as the individual experience is ever widening and deepening, the instincts themselves must be ever changing. They can consequently be modified and improved by 
individual effort, notwithstanding Herbert Spencer's sage remark that "there is no political alchemy by which you can get golden conduct out of leaden instincts."

The most fundamental instinct is that which is known as the instinct of self-preservation. That little word "self" is responsible for much confusion of thought. Its ambiguity causes it to be allied to a number of conflicting ideas, but, in the main, it has opprobrious implications. Thus we speak of selfish, self-seeking, and selfabsorbed; whilst in an opposite sense we applaud self-improvement, self-respect and self-reverence. Professor Huxley once pointed out that an evil effect of superficial education was due to confusion of thought which arose from the ambiguity of terms in current use, and argued that many imagined that they were well educated when they had merely learnt the art of stringing words together without associating with them any particular ideas!

The distinction between egoism and true individuality is of very great importance; and may help us to keep clear from the confusion which arises from the ambiguity of the word self. The characteristic mark of egoism, then, 
is the mental seizing upon limitations, a mere complex reaction,- a futile endeavour in the direction of fixity and permanence in the phenomenal world; while individuality, on the other hand, implies, in its best sense, a continuity of higher effort in the direction of inward growth, expansion and unity. Those revelations of the real correlation of the forces underlying all phenomena which we have spoken of, are a constant accompaniment of genuine individual growth. Such revelations, or true perceptions, have tremendous executive power as compared with the force of mere egoistic tendencies, with which they are generally in conflict, though their respective energies need not in practice be wholly incompatible with one another. Those illuminating ideas and perceptions are indeed the fundamental basis of all true modesty; but modesty must not be confused with timidity.

To return now to the instinct of self-preservation. It will at once be seen that its tendencies and activities may vary according to whether it is acting upon the organism from a higher or lower plane of evolution-whether, that is to say, its energies are directed towards preserving the physical organism merely, or promoting the 
spiritual growth of the individual. This differentiation of instinctive feeling gives rise to a conflict among the complexes ; and all conflict is painful.

The conclusion which we draw from these reflections is that the only real remedy for human pain, as distinguished from temporary palliatives, is such systematic education as will effectively subordinate our lower to our higher purpose. This may be called a truism; but the study of the conclusions of psychology, and their intelligent application to practical life, will help to keep its truth actively in view. 


\section{CHAP'TER II}

\section{EMOTION AND INSTINCT}

WE have seen that emotion is an essential element in the formation of complexes. Let us endeavour to elucidate the matter by means of concrete illustrations.

The ordinary human mind is a crowded aggregation of incipient beliefs, mental habits, concepts, longings and aversions, for the most part instinctive, mere potentialities. There is no such thing as an empty mind: nor is there any unchanging mind. These crowds of beliefs and tendencies are necessarily correlated, and, as the individual life develops, they fluctuate, mingle and conflict.

A proposition presenting itself for consideration, either at the instance of outward circumstances, or as the result of meditations, is accepted as true, or is rejected as false, with varying degrees of hesitation, according to our moods. If the proposition appeals to us as 
decidedly advantageous, that is to say, if it seems to open up the prospect of pleasurable emotion, and if it be not in strong disagreement with some particular habit of thought at the time active, the tendency of the mind is to accept such a proposition as a true pronouncement. Its disagreeableness, on the contrary, at once prompts its rejection. There are exceptions to the latter course in the case of so-called timid natures, whose egoism takes the form of credulity or over-suggestability, coupled with a morbid apprehension of any invasion of the sanctity of their personality: but this exception does not affect the general rule.

Let the proposition, for example, be related to Art, some question of architectural style, a scheme of decoration, the quality or disposition of furniture : we call it a matter of good or of bad taste, according to our predilections. Let us suppose that it is a political question, or one of literature, science, or religion: and that it forms the topic of discussion with acquaintances: if now it should happen that the question is one which excites in us strong feelings, then agreement stimulates mutual interest and sympathy between individuals : often quite irrespective of 
the real character and essential merits of the subject discussed. The tendency also is towards hasty and unwarranted generalization. We are apt to call the people, who agree with us, nice people, interesting and well-informed: while those who disagree with us are ignorant and evilly-disposed! Furthermore, when a proposition is supposed to correspond with what we imagine to be the universal experience of our fellows, tested by observation and accepted on authority, we call it "objective truth." Thus in former days the revolution of the sun and stars round the earth, as centre of the universe, was an obvious "fact," an "objective truth" : and Galileo for holding contrary views was considered an enemy of the human race!

The contention here is not that there are no reliable criteria for distinguishing right from wrong, what is true from what is false; but that they do not exist wholly apart from the element of mind, of which the emotional quality is an important factor in their growth and determination. In other words human judgment is necessarily related to temporal conditions; and at its best it is neither absolute nor final. However much we may insist, as we often do, that 
we are quite impartial in our judgments, and however near some may approach that ideal; yet it can hardly be gainsaid that, in practical life, impartiality is never to be counted on.

Many years ago John Stuart Mill argued with great force that all our accepted rules dealing with the idea of justice and fair play were mere human conventions based upon established beliefs of very slight permanent validity. Such conventions have their value, no doubt, in giving expression to prevalent beliefs; helping men to co-operate, by reminding them of their mutual obligations; but no sensible person to-day would insist that any convention, although it may be embodied in the law of the land, must be regarded as absolutely fixed and irrevocable. Trouble inevitably arises when sections of the community, having lost faith in the authority of certain conventions, find themselves in conflict with the law, while at the same time other sections insist upon the sacredness of the law, as an embodiment of eternal truth. More especially is this the case when, as often happens, the same individuals or groups accept conflicting conventions with almost equal fervour!

The organised life of civilised states has 
developed rapidly, and it has certainly become very complicated, but all the elaborate machinery set up by democracies for the readjustment of laws by means of legislation, and for the alteration of the personnel of administration, appears to be still quite inadequate to cope with the very numerous manifestations of discontent. The demands made in diverse quarters for the greater satisfaction of "natural rights" is becoming daily more insistent. On all sides the cry is the same: "All we ask for is justice"; and few there are who suspect that the only real satisfaction comes from within.

Shakespeare's play The Merchant of Venice was evidently written with the object of bringing home to the average intelligence the great truth that "laws" must be harmonised to conform with mercy; and it is rather curious to note, that notwithstanding our professedly great admiration for Shakespeare, what a confused kind of controversy is invariably provoked by the occasional revival of public presentations of this play.

The spirit of unrest, which at present prevails in all departments of our communal life, both in thought and practice, seems to call loudly for 
the awakening of some higher faith in the purpose and destiny of individual existence; and how is this possible without a serious effort being made to introduce a really moral and religious atmosphere into popular education? For it is difficult to see how all this confusion in our intellectual standards of value can by any possibility be resolved, so long as the egoistic and emotional character of the human mind remains undisciplined and rampant. When, however, the energies of our emotions are subdued or sublimated by alliance with higher ideals, then there is more elasticity and free play between the minor complexes, less danger of their dissociative emergence into consciousness, and as a consequence a clearance of the field for the exercise of our higher powers of perception and understanding.

We have seen that it is instinct which is the foundation and origin of the complexes; and that instinct has a twofold function : first the development, preservation and reproduction of the physical organism, as an individual organism; and secondly the evolution of this organism as an instrument, or vehicle of the higher purpose of the race to which it belongs. These two 
functions may operate harmoniously together; or they may act, if undue stress is laid on one or the other function, in apparent conflict.

Activity due to instinct is either pleasurable, or painful, according to whether it is directed positively or negatively. It is directed positively in the exercise of the nutritive and reproductive functions of our bodies, in the development of the various senses and organs of the body, and in the development of the intellectual faculties. It is directed negatively when it manifests itself as warnings and pains, which arise from the apprehension of dangers, either physical, intellectual, or moral, such as occur in the form of disease, or in the form of violent shocks to the system. The correct interpretation of instinctive feelings is, therefore, of the highest importance to our welfare; and it follows that we should endeavour as early as possible to supplement the instinctive tendencies of our nature by the cultivation of intelligent volitions, and by the stimulation of the habit of rapidly forming sound judgments in difficult situations. If we allow mere pleasurable sensations to prompt our thoughts and actions, thus using what intellectual powers we may first acquire towards the 
gratification of instinctive desires, our instincts themselves become perverted. Such perversion is unfortunately only too common. We see the wholesome appetite for food rapidly degenerate into gluttony. We see the instincts of self-preservation, of sense development, of reproduction and of intellectual growth pervertedintoluxurious living, aesthetic sensuality, lust and vanity.

A great'danger lurks in the oft repeated saying: "Let us enjoy ourselves while we are young and when we can." There is fortunately a happy mean which lies between the extreme of asceticism, of puritanical notions which regard all enjoyment as sinful, on the one hand; and of the opposite extreme, the short-sighted hedonism of mere pleasure seeking, on the other.

The reaction against repression, as an educational ideal, seems to have gone quite far enough, so that we are now confronted with some very extravagant claims as to the "rights of children." Many are apt now-a-days to lose sight of the important fact that habits, growing out of the unrestrained vent given to instinctive feelings in youth, are likely to become very stubborn barriers to the individual's higher intellectual 
and moral development. These habits tend towards' the production of a multitude of irrational and superstitious beliefs, fancies, false and exaggerated expectations. Vague notions of "luck" and "chance" fill the thoughts with an inevitable train of disappointments, resentments and bitterness.

If all instincts were directed simply towards the preservation, development and reproduction of the physical organism, without regard to any higher human purpose, then indeed the continuity of mankind as a manifestation of spiritual life would be impossible. As a fact, however, there are instinctive energies continually exerting themselves throughout the various phases of our intellectual and moral growth; and inasmuch as the healthy development of this growth involves the harmonious interaction, mutually conscious and volitional, between different individual lives, too great importance cannot be attached to the intelligent co-ordination, sublimation and systematic training of instinctive feelings.

One of the most noticeable consequences of the neglect of such systematic training is to be seen in the mental habit of impatience with

P. 
outward conditions; that exaggerated longing for the immediate emergence of tangible results from all efforts and actions; a longing which often finds expression in a futile and vulgar utilitarianism. Then again that narrow outlook upon life engendered by strong feelings associated with an inadequate intellectual and moral equipment,leads to what is known as "cock-sureness"a distressing form of conceit impenetrable to pure reason. The immensity of the phenomenal world, with its balancing tendencies of innumerable conflicting influences, is disputed or ignored; and the pain, which follows disillusionment, finds its vent in pessimism, or in the preposterous doctrine called the "philosophy of discontent."

But patience is not apathy. Energies well directed, first within and then without, lead to lasting results; and unsought for though they be in their outward aspect, their fruit is the growth of a noble character. 


\section{CHAPTER III}

\section{CHARACTER VERSUS REPUTATION}

ARE character and reputation necessarily in opposition to one another? The answer to this question must depend, as in all verbal propositions, on the implication of the words used.

Shakespeare makes Iago say to Othello:-

"Good name, in man or woman, dear my lord, Is the immediate jewel of their souls :

Who steals my purse steals trash; 'tis something, nothing ;

'Twas mine, 'tis his, and has been slave to thousands; But he who filches from me my good name, Robs me of that, which not enriches him, And makes me poor indeed."

This is a striking passage and is often quoted, but, if carefully analysed, it soon becomes apparent that neither from a legal, economic, nor from an ethical point of view is it at all sound. Moreover on another occasion the same worthy says to Cassio:- "Reputation is an idle and most false imposition; oft got without merit, 
and lost without deserving." Now Iago was a clever rascal of good repute, who did not, as a rule, say things with a view to helping his fellow-creatures to arrive at a better understanding of what was true; and in both the above citations he was endeavouring to mislead by specious and fallacious utterances. Good name and good reputation are synonymous; but they do not invariably tally with good character; for the character of an individual is his actual nature, his true qualities, capacities and disposition; while his reputation is the recorded or otherwise expressed opinions, or beliefs, which are generally held in regard to him and his works. There may be much coincidence between reputation and character, but it need not necessarily be so. Both have their proper uses in their respective spheres. It will, however, be very generally conceded as being quite obvious that character, as an aim and as a determining factor in mankind's well-being, is of immeasurably greater importance than mere reputation. Very generally conceded, that is to say, by those, who will pause to reflect; for it must be admitted that the opposite view prevails largely in our practical work-a-day life. 
How does the confusion arise? In the first place it is held, and quite properly, that we can only judge of results, unless indeed we are endowed with super-normal faculties, which, as a rule, we do not possess. Thus the habit grows of looking for results and endeavouring to obtain them, not as a means of forming sound judgments, as to the meaning and purpose of life, but as constituting in themselves the true use and goal of our existence. It is, then, just this inversion of the proper relations of the inward and outward, of means and end, that is responsible for the pernicious custom, widely prevalent, of neglecting, not to say ignoring, the importance of character-training.

One of the worst consequences of this exaggerated regard for reputation is the constant struggle to appear consistent and to gain, by one trick or another, some of the outward marks of virtue, ability, distinction and credibility, rather than to make the effort to develop the higher qualities in themselves. Thus as civilization advances and the complications of life grow greater, we are confounded with the most deplorable waste of human energy in the vain attempt of individuals, groups, classes and 
nations to maintain their position in the eyes of the world; a struggle which manifests itself in that great mass of affectation and vulgar display; and in those varieties of fraud, folly and makebelief, which we all see and deplore, but fail adequately to cope with. It is important to note, however, that this exaggerated and topsyturvy attitude towards the relative positions of character and reputation does not necessitate either the repudiation, nor even the disregard, of one or the other. It is a question solely of the view we take of their relative positions. The point is: which shall be predominant; which is to be subordinated and which is to be considered supreme? For undoubtedly a due regard to reputation has its value in the regulation of our lives. It is a form of discipline which under present conditions cannot well be dispensed with. It is a useful corrective, a test, or measure of practical efficiency, and a strong, though an inferior, incentive, to honest effort. It is not uncommon, for example, to hear people protest that they do not care in the least for what others say, or think of them; without, in fact, having any genuine belief in the truth of their protestation. This reckless pretence that 
one is always following the dictates of "conscience" when, in truth, the actual prompter is some egoistic delusion, whether it be mere vanity or ill-temper, tends by constant repetition to destroy the sense of shame which is a very powerful moral force.

The difficulty of the educational problem, which presents itself when we endeavour to inculcate the superiority of character to reputation, lies in the fact that the early stages of child-development depend so largely upon the feeding and cultivation of the minor complexes, in which narrow egocentric thoughts and feelings must necessarily predominate. The problem then assumes this form : how are we to counteract these budding and multifarious egoisms in the minor complexes without destroying all incentives to effort? This problem is the subject of the next chapter. 


\section{CHAPTER IV}

\section{INCENTIVES TO EFFORT. ECONOMICS}

WE exert ourselves to obtain pleasure and to avoid pain; to reach out towards what attracts, and to escape from what repels. Experience teaches us what is good for us. Thus stated the question of our incentives appears simple enough. But in reality it is not so.

A child sees something that looks good, or smells good, and so thrusts it into his mouth. He may find it bitter, or too hot,-not at all what he expected. Grown-up people likewise are deceived by their senses, by their opinions, by their false inferences and expectations. What is learnt by experience one day may have to be unlearnt the next. Further, similar objects may appear attractive at one time and repellent at another. Even at the same moment we may be both attracted and repelled by the same, or what appears to be the same, course of action by different sides of our nature, by different complexes in short. 
It is true, of course, that certain customs and beliefs have gained general acceptance as a result partly of experience and partly of tradition.

Let us examine some of these accepted beliefs. Physical and mental enjoyment, resulting from the exercise of the senses, bodily exercise, rational intellectual pursuits and diversions, which meet with approbation, applause, or "legitimate success," and which result in personal advancement in the eyes of the world ; a life, in short, of distinction, pleasure or ease ; any, or all these aims, are, by tacit consent, recognised as worthy objects of existence; and advantageous, not to say necessary, incentives to effort. The making of adequate provisions for securing and perpetuating such obviously good things, is called foresight, prudence, commonsense. Yet, strange to say, we can, in certain moods, admire far more the motives of those who systematically discard all such aims as these. In our higher moods the ordinary outlook upon life appears to us, not as commonsense, but as commonplace, selfish and vulgar !

That beautiful word love is much used and 
abused in describing human motives. It is, in fact, associated with two distinct ideas having opposed tendencies. Correctly it is used to denote that expansive force in our nature arising out of a surrender of egoistic thoughts and feelings; but it is also used as applying to the extension of our egoism as allied to the sense of property and possession. In this sense it would more properly be termed affection. In its best meaning, love is indicative of the highest religious emotion, not the mere profession of a creed, nor mere devotion to ceremonial observances, but as indicating reverence for the eternally true, and the divinely beautiful in both man and nature. In the other sense, love implies a mere attachment to our belongings, or would-be possessions, such as our homes, families, friends. Thus an individual says he loves, when he speaks of the things that are particularly his, or the things he would like to have. He says :-I love my home (or our home), my family, $m y$ friends, my art, $m y$ country, my religion. These objects may certainly be shared with others, but mixed with the idea of exclusion and proprietorship. This is not true love, but affection. It is only when 
the egoistic feeling is in abeyance that we can truly be said to love. Then indeed we see life in its proper perspective. We are then able to perceive that the basis upon which the great bulk of human motives rests, is the sense of separateness; that sense which arises from our deeply rooted belief in our physical and psychic isolation. In that belief we develop most of our ideals, we seek our security, and we formulate our plans.

However much we may protest that this belief is delusive and misleading, its almost universal existence is a hard fact, a fact which has to be reckoned with and provided for, if we would deal with our fellow-men. What is more, an adequate understanding of its true meaning and implication, its force, scope and limitations, must be acquired before we can make any serious progress in any attempt to remove its baneful influence by means of education.

It is to the sense of separateness that the economic fabric of our lives is due. Economic systems at once emphasize the fact of its existence, and supply, though only partially and imperfectly, a means of escape. This sense of separateness, as it obtains in the ordinary 
human mind, is somewhat distorted, perverted, and, so to speak, uneducated. It tends to promote error of judgment in so far as it makes the temporary and conditional limits of perception appear absolute and final. It obscures one of the most fundamental facts of life, for, whether we know it or not, we are necessarily interdependent, we must perforce co-operate with one another, however much we may hug the belief in our independence. Herein arises, by a process of inversion, a strange anomaly. We have come to regard money, the very instrument forged by long ages of civilization to unite our energies in productive activity, as the real basis of true independence ; as indeed the only effective and honourable means of securing freedom in our lives!

It is often assumed, as a self-evident proposition, that finance is an absolutely essential factor in the production of life's necessaries. A moment's reflection would convince us how absurd the proposition is, for it does not require any great stretch of imagination to conceive of a state of existence in which human beings had learnt to co-operate spontaneously for their mutual aid, without requiring any cumbersome 
machinery for measuring, checking and regulating their individual and collective activities. History has, in fact, furnished us with examples of such true community of interest and endeavour. One might instance the building of some of our finest cathedrals. Even to-day the best part of our social life has a non-economic basis. The suggestion is not that we could forthwith dispense with our economic system, or even that at this stage it would be advantageous. The point is, that finance absorbs too much of our thoughts, and wrongly. The economic sphere has become too dominant, too insistent; it no longer occupies its proper place in our lives. The instrument, or servant, has become master !

Why is this? It is the outcome of that process of perversion, or rather inversion, already referred to in the last chapter. Civilization has developed very rapidly. The application of our minds to material considerations has, in proportion to our moral growth, been somewhat overdone, and a readjustment, a systematic co-ordination has become necessary.

Money is supposed to be a standard of "value" and a measure of "value." Much has been written as to the meaning of value. It is 
not, however, necessary to enter here into the technical minutiæ of economic science. From a psychological point of view, value is the mental estimation of what appears to us good, or desirable; but seeing that such estimation varies from time to time, both with the same individual according to his conditions and circumstances, and with the different individuals into whose lives we enter, it is evidently a bootless task to attempt to fix, or define, some measure of value so as to give it anything approaching to universal application. Money, no doubt, has its own function in its proper sphere, but the mistake we are constantly making is to try to measure by its means that with which it is altogether incommensurate.

The delusion that money is an universal power, meeting all human needs, is a superstition amounting almost to idolatry.

Those moments in which we feel and perceive the underlying oneness of our lives are, it must be admitted, very rare. We do not at all times and in all circumstances realise our essential interdependence. Our whole natures have not yet acquired the capacity of giving and receiving freely. There is that in us, more especially as 
regards what we call our material interests, which demands a quid pro quo for services rendered and "benefits" exchanged. It is our "dignity," we say, which demands it. Our "selfrespect" requires it. Why, without such demand "we should be the prey to the idle, the greedy, the vicious!" But that which really makes the demand is the innate egoism of our rudimentary natures, however much we may dress it up in high-sounding phrases. It is egoism which creates economic values just as certainly as it creates vice and greed and indolence.

Let us be clear about this before we set about to find the remedy for our present ills.

Viewing the various social and political institutions of our times with honest and impartial judgment we cannot help seeing that they are all, more or less, built up on what is termed an economic basis. Whatever may be the superstructure, the foundation, or legal status, is one of "property," "endowment," and "contract." Religious, charitable, philanthropic, educational, industrial institutions, the institutions of marriage, of birth, of rank, of social procedure are all incorporated under the laws of contract relating to property, for privileged, 
or exclusive use. Their dignity, prestige, honour, the measure of their freedom, power and stability are generally estimated in terms of money. Persons and institutions without property have "no stake in the country." Indeed with many people money has come to be regarded as a substitute for exertion, as the only true refuge and safeguard; even also as a means of covering over and concealing vice! Money is the power most admired, most respected, most coveted by the mass of mankind to-day, rich and poor alike ; who are rapidly coming to consider that the "struggle for life" is a financial struggle, pure and simple!

That this should be the state of civilization in which we find ourselves placed, is evidence of the way in which we have been brought up, and of the ideals under whose influence we have grown to be what we are. The facts need not be insisted on in any carping, or malignant spirit, but if we would emancipate ourselves from this thraldom it must be boldly and frankly recognised.

The ambiguity of the term "wealth" is a serious difficulty, for it has a strictly limited signification in the sphere of economics, and it 
is used in a far wider sense in general literature and poetry and also colloquially. In its technical meaning, wealth is that which can be recognised by law as property, either personal, or collective, which can, therefore, be made the subject of bargain and contract; and which has in consequence an "exchange value." Beneficence, in a spiritual sense, is in no way implied in the conception of economic wealth, any more than the idea of true self-sacrifice can be involved in the motives of economic gain. The power of spiritual beneficence is, no doubt, stupendous in its own sphere in the determination of human welfare, but it belongs to a quality of thought and action fundamentally distinct from those obtaining in the world of economics. In our dealings with one another these two spheres may indeed seem to be inextricably mixed up, but with the help of a higher insight they can be distinguished, and if we are wise we should endeavour to avoid all unnecessary confusion between them. Services rendered from motives of true love, services rendered with the spontaneous feeling and conviction that all our truest interests and ultimate ends cannot be in any sense opposed, is essentially free service. Such 
service is altogether unlike a business transaction, for it is not something which can be bought and sold. We are fortunately, most of us, aware, in some parts of our lives, that humanity is capable of acts of true kindness ; and we know that, while such acts generally inspire a kind of reciprocity both in substance and feeling, they involve no definite provision for any return in the nature of a stipulated "consideration," or quid pro quo. In legal parlance they are "acts of grace," which cannot be made the subject of litigation for the enforcement either of benefits, or pains and penalties.

The aims of commerce, as commerce, are those of self-preservation and self-gratification, both in a very narrow sense ; and self-aggrandisement, in a worldly sense ; strictly personal, or for our belongings. The methods of commerce are those of strenuous competition.

If we concentrate our energies upon commercial pursuits and deliberately adopt their methods, aims and ideals, as our own, making them the dominant purpose and mainspring of our lives, to the neglect, or subordination of our spiritual capacities and potentialities, we can, beyond doubt, achieve a certain kind of 
temporal success; but the spiritual side of our nature will not for ever be denied. Some crisis will arise, whether it takes the form of disease, disaster, or death, which will find us unprepared, and shatter the fabric we have made. This is no mere hypothesis, but the universal experience.

It is often urged that the two sides of our nature can be made to work hand in hand. Possibly, but the important question is : which shall be dominant? Unless we constantly keep our minds clear on this point, the risk is very great. It is easy enough to say, as many do, that we will first make our worldly position secure, and then use the vantage ground, so gained, to "do good" afterwards. A strenuous commercial life as things are to-day, is not the best school for learning the nature of good, or high moral purpose. Many there are who learn too late that there is truth in the saying that one cannot serve both God and Mammon.

The real remedy for our ills is to be found, and found solely, in sound educational methods; and this is not possible without knowledge of the composition and working of the human mind. This knowledge must in the first instance be 
gained by teachers, and it must be skilfully and fearlessly applied in practice.

We have seen that, by enlarging the field of vision and consciousness, complexes can be united, resolved and co-ordinated, so extending and purifying the sphere of experience and volition; and that the real strength and greatness of individuality lies in the direction of the impersonal. These are fundamental facts handed down to us by the noblest traditions and confirmed by experimental psychological research.

The genuine understanding of these fundamental facts would lead to the remodelling and readjustment of our whole educational system. Competition as an incentive to effort (and incidentally as the great fostering cause of egoism) would be abolished. Punishment would be mitigated. Bribes would disappear. Children would be discouraged from assimilating false ideals while their minds are young and plastic. Nobler ideals would be placed before them and we would contrive, by suitable examples and illustrations, to make these appear really interesting and attractive. Ideals so instilled tend to become instinctive and would have vastly 
greater weight and influence over life and conduct, than mere intellectual concepts, acquired later in life.

These higher instinctive aims, thoughts and feelings, ever seeking their expression in action, would, as life continues, extend their scope, strengthen their energies, and bring the individuality into more harmonious communion with other individualities, and with the outer world. The truer the instincts, the more real becomes the growth of the individuality in the direction of the impersonal.

In the incompletely developed mind the field of vivid consciousness, being necessarily narrow and circumscribed, a vast number of life's operations must pertain to the instinctive order. In psychical research these are what have been termed "automatisms." In using this term it is important to bear in mind, however, that such instinctive acts are by no means removed from all element of responsibility. It is true, no doubt, that automatisms, while functioning, have the effect of committing the individual without his having been fully aware of what he was about. Inasmuch, however, as they were the outcome of some, it may be, innumerable 
conscious efforts, or musings, they must be regarded as being in fact, the deferred consequences of previous volitional activity. These considerations add point to the insistence upon the value in psychological study to the healthful and systematic governance of our lives. With a proper understanding of the laws of complex formation, and of the laws which regulate their interdependence, emergence and co-ordination, an immense diminution could be effected in human suffering and worry. By means of such understanding we could substitute comparatively simple and direct methods, for the cumbersome experiments, failures and false inferences which characterise the ordinary processes of social evolution. 


\section{CHAPTER V}

SPECIALIZATION

THE innumerable divisions and subdivisions in the organised life of a community renders some kind of specialization as regards instruction and training a virtual necessity. The various departments of State, the division of labour in productive and distributive enterprise, the growth differentiation of professional occupations, of scientific research and recreative pursuits, all these tend to create an imperative demand for specially equipped and efficient workers, and as a consequence for "vocational training."

In recent years specialization has grown very fast and has already produced surprising results; but carried to extremes it has very serious drawbacks. For it has the effect of narrowing down the individual outlook, and of isolating, or dissociating, the component parts of the social organism; with the result that efficiency is, on 
the whole, not gained, but lost. The pernicious craze for " record breaking" ; that extravagant longing to achieve something striking, or sensational, something that will "stir the public mind" to admiration and applause, fosters a most unwholesome influence in our midst. The concentration of people's thoughts and imagination upon the ephemeral data of outward events, as though these constituted in themselves the object and goal of existence, must tend to divert attention from really important matters, to distort and confuse our sense of proportion; and make us lose sight of what is fundamentally essential to our welfare and true progress.

Not so very long ago it was very commonly held that by a vigorous application of the mind to no matter what subject, one could thereby develop certain important "faculties," which were called "the will," "the memory," "the power of concentration," and "the power of observation"; and that once gained these "faculties" could be applied to any and all purposes! Modern physiological and psychological research has utterly exploded this doctrine. This research clearly indicates that observation, memory, concentration and volition are developed only in association 
with specific ideas, emotions and actions ; that the development of these mental powers, along certain lines, involves the development of specific portions of the brain and nervous system; and that, for the higher purposes of our communal life, or for any purpose, other than those so specifically developed, these awakened powers of the mind are quite useless; unless, indeed, there is an adequate extension of the associative process, linking the specific complexes, so formed, with other complexes, especially with the more general, or co-ordinating complexes.

An uneducated farmer, calling at a country house to obtain the signature of a local magnate tosome document, was asked to wait in the library. He afterwards expressed to a friend his astonishment at the large number of "Bibles," which he had "observed," stored up on the shelves. The Family Bible was the only book with which he was familiar and it happened to have an outward resemblance to the books in the library. Hence his inference as the outcome of his "observations"! But let the owner of the library, the educated man of affairs, quite uninstructed in practical agricultural operations, walk the fields with this man of the soil, and the tables would be 
turned; all his widely cultivated and scholarly powers of observation would serve him but little, and, as likely as not he would make just as foolish observations as that of the uncultured farmer. So it is in other fields we will find observation, knowledge, volition, linked with the memory of what is familiar.

"Familiarity breeds contempt" expresses only a half-truth, for familiarity also breeds affection and interest. But it is true that phenomena familiar to an expert, a specialist, may seem utterly commonplace to him and to his fellowexperts, while to a non-expert, or to an expert in another line, the same phenomena may appear to be very wonderful and mysterious, so long as they are still unfamiliar.

It is difficult, no doubt, but few things are more important in education than to bear in mind, and to inculcate, the changing nature of everything and everybody. There are, of course, degrees of duration, but nothing is absolutely static ; everything is related, conditioned and transitory. The nearest approach we can make to fixity and permanence is to be found in our enunciation of fundamental principles, or laws; but even here it must not 
be forgotten that such enunciations are themselves dependent on our powers of expression and understanding; by no means immutable factors.

The common practice of labelling men according to their chief avocations is responsible for much unnecessary confusion; and it is sometimes a serious bar to our estimation of the real worth of an individual. We often hear such contemptuous exclamations as:- "What can a lawyer know about farming?" "How can a doctor make a good man of business?" "Let the shoemaker stick to his last," and the like. The idea being that competence in one special line must necessarily involve disqualification for proficiency in other directions. Generalizations of this sort are just as misleading, in their own way, as their opposite extremes, to which reference has just been made. For they leave out of account a very valuable human quality, namely versatility, which, though often spoken of disparagingly, is essential to good citizenship. It has frequently been noticed how a first-rate lawyer, a highly skilled journalist, or a prominent statesman can, by strenuous application, and a short term of study, become 
thoroughly expert in almost any branch of knowledge.

True versatility is acquired by the sublimation and a drastic subordination (not the repression) of the emotional element in most of the complexes. A versatile individual is one who has, in his own person, exemplified the process of co-ordination, whereby his higher complexes are awakened. 


\section{CHAPTER VI}

\section{MULTIPLEX ENVIRONMENT}

THE mental habit of differentiating all life's experiences into "subject" and "object," of drawing a rigid line of demarcation between these mental products, and of calling the object the "reality" - the "actual fact," as distinguished from what is supposed to represent merely transitory subjective states, is a habit which has become so deeply ingrained in the human mind, that it is difficult now-a-days to induce anyone seriously to consider a question from a different point of view. Indeed it is this deeply ingrained mental habit, with all its definitions, categories and other conventions, which forms the basis of the "exact sciences." Yet it is admitted by all trained thinkers that our knowledge of matter and its qualities, our conceptions of time, space and motion, all in short that we believe concerning life, growth, form and substance, is reducible to more or less systematised mental phases, or concepts, arising out of sense experiences. 
It is true, no doubt, that our general powers of observation lead us to infer that every living organism is capable of experiencing such definite recurrences of physic phases ${ }^{1}$ with such regularity and persistency as to indicate seemingly the existence of an "environment" independent of the organism itself. We cannot, however, properly, be said to know the existence of anything beyond our mental states. We know, in other words, the occurrence of phenomena, and we infer the laws of their relation and causation, but we do not know of their independent existence.

It is particularly important to be clear on this point, because the term phenomenon is now frequently used, not in its proper philosophical signification of an appearance, but as the equivalent of reality, of "the objective truth."

"The truth" is, indeed, an expression very commonly employed, though improperly. It is, in fact, an abstraction, the discovery of which can, in a sense, be aimed at, but that which we actually find, and which we can properly be

${ }^{1}$ It should be noted here that the phrase "physic phase" used above does not necessarily involve such individualised developments as consciousness, or perception. 
said to know, is the true, the relation between one physic phase and another. All this is quite elementary, but it is important to bear it in mind.

What, then, we do, when we have phenomena under observation, is to differentiate or polarise experience in accordance with well established mental habits, and under the operation of more or less ascertainable laws of mind. Individual observers, however, are not isolated, and they can, in varying degrees, share each other's experiences. It is this all important fact which is the true inwardness of the Christian saying : "We are members one of another." To use the term mind, in its broad signification, is to designate that power or principle which is common to all existence. Mind does not exist solely in its transitory manifestations, as consciousness and perception. It is an aspect of manifestation of all that is, whether we call it animate or inanimate, material or spiritual. It is the basis of all experience. The ordinary individualised mind is partly "unconscious," latent, undifferentiated; the rest is either "conscious," or "sub-conscious," in extent or proportion respectively, according to the individual's 
development, qualities and circumstance. There are, of course, as we have seen, varying kinds and degrees of the conscious and the subconscious, but what we are concerned with at the moment is the fact, that a great region of mind is neither conscious nor subconscious, but still is mind potentially and the existence of which is actually felt when we engage in the operation of observing fresh phenomena. Thus "environments" are aspects of mind which vary indefinitely according to their observers, whether individual or collective, according, that is to say, to the experiences through which they are evoked. There are, however, always three kinds of environment corresponding to specific experiences. These are: (1) the environment due to unconscious mind, unassimilated to individualised life and practically universal; (2) the environment due to the subconscious mind of the observers, which corresponds to the "Zeitgeist," or "Herd instinct" (somewhat of a misnomer), and it is from this environment that fashions, customs and conventions have their rise; (3) the environment due to the vivid waking consciousness of individual or collective observers.

The most truly valuable of all experiences 
are those in which all three kinds of environment are evoked, or manifest themselves, harmoniously together. That is to say, when consciousness is, so to speak, focussed concentrically through them all. This form of experience is, generally speaking, the outcome of perfect health and sanity.

Once these fundamental conceptions are grasped by the reader, he can extend, apply and illustrate their meaning by reference to his own personal experiences.

It might be objected, perhaps, that all personal experience implies the pre-existence of a separate subject, or self ; but this objection is nothing more than a re-assertion of the determined habit of differentiating all experience into subject and object. That this habit prevails is not now in question, and there is no immediate dispute as to its fundamental importance to individual existence; but the formulation of such an objection, in a philosophical discussion, indicates the obtrusion of what may be termed an intellectual complex of a pronounced egoistic type. The formation of this complex is, in fact, one of our chief difficulties, for it may be strongly emotional as well as intellectual, and 
it constitutes a serious bar to healthy mental development. If, however, it does not assert itself too strongly, we are enabled to perceive that experience is not, and never can be, a simple duality, consisting of subject and object only; but that in all experience there is present a third element, or aspect, or term. In other words a knower and a thing known, implies knowledge: a perceiver and an object perceived, implies a perception. In all experiences these three terms must necessarily co-exist; and inasmuch as each term bears a determinative relation to the other two, any attempt to dissociate them, to treat any one or two of them as though they could exist apart independently, must lead to error. The slightest change in one implies a change in all. Thus a sequence of experiences, in time, involves a respective modification in these three variables.

When we speak of a series of "events," we make use of a customary convention, which certainly suggests the fixity and independence of one element, the objective, in this trinity of experience. That this convention has great value as an expedient for our practical convenience, in view of the well-established polarisation 
habits of thought, is undoubted; but that the convention is not only fallible in its applications, but is productive of strife and confusion, is evident from a conflict of testimony adduced in every lawsuit; in political, scientific and religious discussions ; and in that aggregation of irreconcilable data, which is compiled in the name of "history."

The fact is that the actual determination of one or of two elements of this experience trinity, isolated from the rest, is not possible, any more than it is possible to make one or two straight lines enclose a space. Yet it is this impossible task that the human personality is ever endeavouring to accomplish. One of the results of this endeavour is the evolution and multiplication of concepts or ideas in very great variety and complexity. As humanity is at present constituted the process of concept erolution is quite necessary, and within their proper sphere of activity these concepts, however various and complex, are, of course, of very great practical utility ; but for man's true mental development, their subordination to the higher evolutionary processes, both in the individual and the race, is absolutely necessary. 
The cramming of the individual mind with a large number of concepts, with their names, symbols and formulæ, may indeed result in the acquisition of a specific variety of intellectual efficiency, related to that system of thought to which the concepts belong; but unless there is, at the same time, an awakening of some perception of the proper limitations of such a system and of its essentially relative nature, this mental cramming will be a hindrance rather than an assistance to higher intellectual growth.

Let us take, for example, one of the most important generalizations of modern science, namely that of "energy." Energy is said to manifest itself as light, heat, mechanical work, chemical affinity, electricity, etc. Energy manifested in one form can be transmuted into its equivalent in another form and then back again into its original condition without loss. The transmission of force in railway locomotion will serve to illustrate the theory of conversion and conservation of energy. The potential chemical affinity of the fuel burned in the furnace of the engine is converted into heat. Part of this liberated heat energy is dissipated by conduction and radiation, but is all scientifically accounted 
for. The remainder of the heat energy is converted into mechanical work through the expansive force of steam. This mechanical work is expended in overcoming the "inertia" of the moving mass, and at times also in overcoming the force of gravity. Ultimately, through the resistances of friction and of "concussion," the energy of mechanical motion is re-converted into heat.

From the restricted point of view of physical science, energy is constant, unchanged and unchangeable. From the point of view of psychology, however, nothing remains the same, and all the modification in the manifestations of energy is determined by the directive powers of mind. Thus in the illustration above cited this directive power is, in greatmeasure, our corporate intellectual life ; and quite obviously it is of material importance that the mechanical energy of the moving mass should be systematically re-converted into heat through the agency of brakes, rather than through the more irregular mode of a collision !

The directive and co-ordinating powers of mind, in the determination of the manifestations of energy, vary according to the varying forms in which life's processes are organised. 
Thus, in the functioning of the human organism and of animal organisms generally, (viewing these primarily as vital organisms,) the directive powers take the form of conscious, subconscious, or unconscious activities, usually in combination. In the functioning of vegetable life, they are for the most part unconscious, but also collectively subconscious, using this term in its broadest signification. While in the mineral kingdom the directive powers, though still mind, are strictly unconscious. (See note p. 5, Chapter I.)

We come, therefore, to the conclusion that there is a great multiplicity of "environments"; and that these exist, not wholly apart from and independently of physic phases, but as complementary to them, in their multiplicity. Further, that the awakening of our higher powers of synthetic understanding enables us to perceive that through their fluctuations and mutations all psychic phases, whether we regard them in the light of "environments," states of "consciousness," "subconsciousness," "unconsciousness," or of "concepts," are necessarily correlated and interdependent, and that they are, without exception, subject to the reign of universal laws. 


\section{CHAPTER VII}

RELIGIONS, IDEALS, THE TWICE-BORN

Few subjects present greater difficulties to the art of definition than those arising out of that confused maze of conflicting ideas, customs and traditions associated with the word religion.

To say that religion is the sphere of human thought and practice, which pertains to the unmanifest side of individual and communal life, or what is usually termed the region of the "unseen," does not really carry us very far; for religion brings us in contact with those deep and intense convictions in the mind of man which have impelling forces greater in their scope and more enduring in their effects than those which arise out of physical conditions alone. But these convictions are of various kinds and they impel men in different directions. They unite men into groups, they divide groups into sections, and they isolate individuals one from another. Religions, religious institutions 
and sects are almost innumerable. Their existence is based upon an immense variety of seemingly incompatible traditions, customs and creeds, which in their turn are associated with all kinds of human passions, good, bad and indifferent. Further, there is no fixity in religious systems. Like physical organisms they grow in strength to fruition and then decay. One religion appears to spring from another, or its life may be enriched and impoverished by the assimilation of ideas and influences derived from several sources simultaneously.

Notwithstanding, however, all the confusion and perplexities which surround the subject, it is possible to discern, underlying the religious history of mankind, certain clear conceptions of priceless value; conceptions as to the aims, purposes and destiny of human life; conceptions determining the emotions, conduct and language of individuals and races; but all such conceptions belong properly to the domain of psychology.

It may be confidently asserted that practically every individual, with scarcely any exception, has at some time or another undergone distinct religious experiences. Experiences, that is to say, which exalt the mind to a state of ecstasy ; 
and whether it be the ecstasy of awe, of hope, or of rapture, such states of mind indicate for the individual his partial awakening to a perception of the real meaning of the existence to which he has been born.

William James in that illuminating work Varieties of Religious Experience, has shown that there is a great similarity in the essence of these experiences, as distinguished from the mode of their separate occurrence. He contended, however, that, in a great majority of cases, the intellectual capacity of the individuals who have these experiences is not adequate to a full and proper interpretation of their meaning; and that even when they are understood, the understanding is very rarely accompanied by the power to give such expression to their meaning in words as would carry conviction to the minds of others. Yet there is an abundance of evidence adduced making it perfectly clear that many of the experiences belong to the same order; and that they must have been very real indeed to those who underwent them.

Several cases are cited in which a great mental revulsion takes place, a revulsion amounting to "conversion," or "change of 
heart." In these cases the whole personal outlook is radically altered. Interests, tastes, aims and habits are transformed. The most intimate disposition seems to be fundamentally modified and renewed. The narrow and shortsighted self-interest, which actuates the ordinary individual life, gives place to higher human interests. The love of pleasure and gain yields to the love of truth, or, as they generally prefer to express it, to the love of God. Lust, anger and pride are subdued, while the individual energies so liberated find expression in benevolent activities. But, as William James points out, these changes of character are often neither so sudden nor so radical as they appear to be.

It will be remembered that, in the first chapter, personality was compared to an iceberg. Now an iceberg, unless it happens to be stranded, is a great mass of floating ice of which a small fraction only can be seen above the surface of the water. Ordinarily speaking, we depend upon our physical powers of vision in order to determine the size, shape and position of these very formidable obstacles to safe navigation, but we have learnt, at a severe cost, how unreliable this dependence upon mere eyesight can be. 
The floating mass is continually shifting its centre of gravity. Occasionally, therefore, it happens that suddenly the visible portion disappears from view, and another portion, or it may be several portions simultaneously, emerge from invisible depths. Similarly what might be described as the centre of force in one's personality is subject, on occasion, to rapid and momentous changes of position in relation to the correlated system of complexes out of which the personality is composed. It is just these sudden changes in the centre of force which are often spoken of as "conversion." Those portions of personality which emerge from the subconscious in our altered condition, are not, in fact, newly created entities, they are merely transposed, and thus, for the time being, rendered dominant. What is more, the new position may resemble one of "unstable equilibrium," and it even suggests, to those who take a too rigid view of a fixed hypothetical self, a want of genuineness in the conversion; but, by a careful investigation of a large number of cases, William James came to the conclusion that simulation was not the true explanation of the changed life, which followed upon conversion. 
The true explanation is briefly this : certain ideas, which correspond to what may be called the religious beliefs of others, are assimilated intellectually by an individual. In other words these ideas become familiar, in a kind of unattached manner, to a group of complexes, which, linked together for practical purposes, constitute the normal waking personality; but the emotions properly associated with these ideas belong to another group of complexes, which are, for the time being, instinctive, subconscious, or latent; and to these they gravitate and with them they coalesce. This process continues until this latter group has gained sufficient inherent strength, aided perhaps by some special outward circumstances, to force its emergence into vivid consciousness.

It is obvious that such spasmodic conversions have their drawbacks; and that the steady persistent growth of high character is far preferable. If one might venture upon an extension of the iceberg simile, a permanent change of heart would be comparable to the actual melting of the ice itself, so that its waters may combine freely with the waters of the ocean.

This last suggestion brings us to a point of 
great importance, namely, the extremely limited value of all imagery, and the great danger involved in dwelling upon a supposed analogy, which, though it may offer some passing help in the effective expression of an idea, cannot be properly regarded as the only symbol conveying that idea, or true for all time. More especially is this the case when we are endeavouring to explain some aspect of a process deep and far-reaching as is the growth and evolution of human individuality.

Images, phrases and formulas, which have been either invented or evolved for the purpose of conveying great truths, are undoubtedly quite necessary as educational instruments. But the inveterate tendency of the human mind to dwell needlessly upon such instruments, inverts their proper relation in thought to the truths they are intended to teach; and hence there arise all the evils of dogmatism and idolatry. A well made scaffolding, erected upon a sound system, is a useful contrivance for enabling us to build a great edifice, but if we forget the purpose for which the scaffolding was contrived and so erect it that its subsequent removal would endanger the stability of the edifice itself, it will readily 
be seen that it was not fulfilling its proper function. The application of this principle to education may not be quite so obvious, but it can hardly be less important. Creeds, conventions and traditions, by long use and familiarity, breed in the mind of man those egoistic affections and attachments, which, with their restricting influence upon perception and volition, bar the way to spiritual growth and understanding. In this way the vehicles, instruments, servants and friends, which man has created for his higher purposes and ends, tend to become his most formidable obstacles and his deadliest foes.

What is a true ideal? Can it exist apart from the vehicle through which it finds access to the human mind? This is a difficult metaphysical problem and it is not necessary to solve it here. But perhaps the best way of dealing with it, is to show that practically the same ideal may be found embodied in a great variety of different dresses and shapes. This is the province of comparative religion and philosophy; and already much excellent educational work has been done in its fields.

In the framing of ideals, and in order to make sure that they are really true and likely 
to be helpful towards furthering the perfection of mankind, it is important, in the first place, to form some clear conceptions as to the goal towards which humanity is tending. As to this, there seem to be prevalent two sets of ideals opposed to one another. In both human happiness is the goal. According to one set of ideals the world is to be made a better place to live in. Our notions of what is good for us are to be accepted as practically fixed, while circumstances and conditions are to be adjusted to suit them. According to the opposite set of ideals we must take the world as it is, call it "Nature" and adapt our tastes and notions to suit it! It will be surmised from a perusal of the preceding pages that, according to the psychological view, both sets of ideals are equally fallacious. Happiness can only be real and lasting when we have entirely overcome that grasping attitude of mind which seeks to fix either mental disposition or environment as being capable of maintaining respectively permanent independence apart from one another.

It is the conquest of this grasping disposition of heart and mind which is the true meaning and implication of the process of being "born 
again in the spirit." All ideals which conduce towards the attainment of this blessed state are, therefore, from a religious point of view, worthy and noble; all others are false and misleading.

The way or path towards the attainment of this state is accompanied by higher instinctive efforts, but it is essentially a rational way, using the term rational in contradistinction to mere intellectualism based upon the formation and arrangement of concepts. It is thus a process of rationalising instincts, subordinating those of reproduction and preservation to those innate spiritual tendencies, which make for human perfection, or wholeness. Mere devotion to noble ideals is not sufficient. New and keener mental powers and faculties must be developed and maintained. Mere repression is useless. No part of our nature can be ignored in the spiritual process. The lower instincts have to be sublimated, not denied. Unless this is thoroughly accepted and understood, the individual can never gain any lasting confidence and security. The process is called painful, but although it is true that great suffering is involved, the pain which has to be endured is more than counterbalanced by the joy of 
achievement, and is ever diminishing in intensity.

In our efforts towards perfection there must be true self-examination; not mere intellectual introspection. The recorded wisdom of our predecessors, and that of contemporary thinkers, is certainly of some avail, but each individual must rely chiefly upon his own inward efforts to break that crusted mass of ignorance, preconception and prejudice, which we all inherit. In the end, no doubt, one finds that these efforts and the glorified traditions of the past are really identical in purpose; but the actual discovery of this identity and the realisation of its truth is part of the process which each individual must necessarily undergo for himself.

Then can we not help one another? Yes, surely. As William James points out in his Varieties of Religious Experience the practice of "confession" may have very great value psychologically, provided the confessor has a large and well equipped mind, which unfortunately is not usually the case. He should be thoroughly well versed in psychology, and he should be possessed of more than an average knowledge of the affairs of the world. He 
should also be sincere, kind-hearted, disinterested and, above all, he should be endowed with a large fund of commonsense. The professional "confessor" is rarely so equipped, and, consequently, the operation in his hands may be worse than useless.

It often happens, at the present time, that those in trouble fall back on the doctor or the lawyer for advice and guidance. Is it too much to hope that some day, in the distant future, the properly qualified doctor, surgeon, lawyer and teacher may each and all of them combine in themselves the highest functions of both priest and healer?

Careless, or unskilled discussions may sometimes have the effect of awakening the great complex, the whole personality ; especially if it has been awakened before, or even if it has previously been on the verge of an awakening ; but more often such discussions, when they effect a change in the point of view, have merely been instrumental in altering the field of consciousness, by bringing another unimportant complex into the focus of awareness.

As indicated in Chapter IV, great importance attaches to the development of higher incentives 
to effort. How often we repeat or refer to the "Sermon on the Mount," and pay lip service to its beauty and its truth! But what is its true meaning? "A counsel of perfection" is the glib official reply. Certainly, but has it no practical value, and, if so, what is it intended to convey? Restated in cold prosaic language, the lesson there inculcated urges us to rely less upon the seen, the concrete, the physically tangible; and more upon the spiritual side of our natures, unmanifest to our senses, but none the less real and permanent. We are there told on authority that by this way we gain true security and everlasting peace.

It is the object of these pages to point out that this teaching is in strict accord with the conclusions of recent psychological research 


UNIVERSITY OF CALIFORNIA LIBRARY

\section{BERKELEY}

\section{THIS BOOK IS DUE ON THE LAST DATE} STAMPED BELOW

Books not returned on time are subject to a fine of $50 \mathrm{c}$ per volume after the third day overdue, increasing to $\$ 1.00$ per volume after the sixth day. Books not in demand may be renewed if application is made before expiration of loan period.

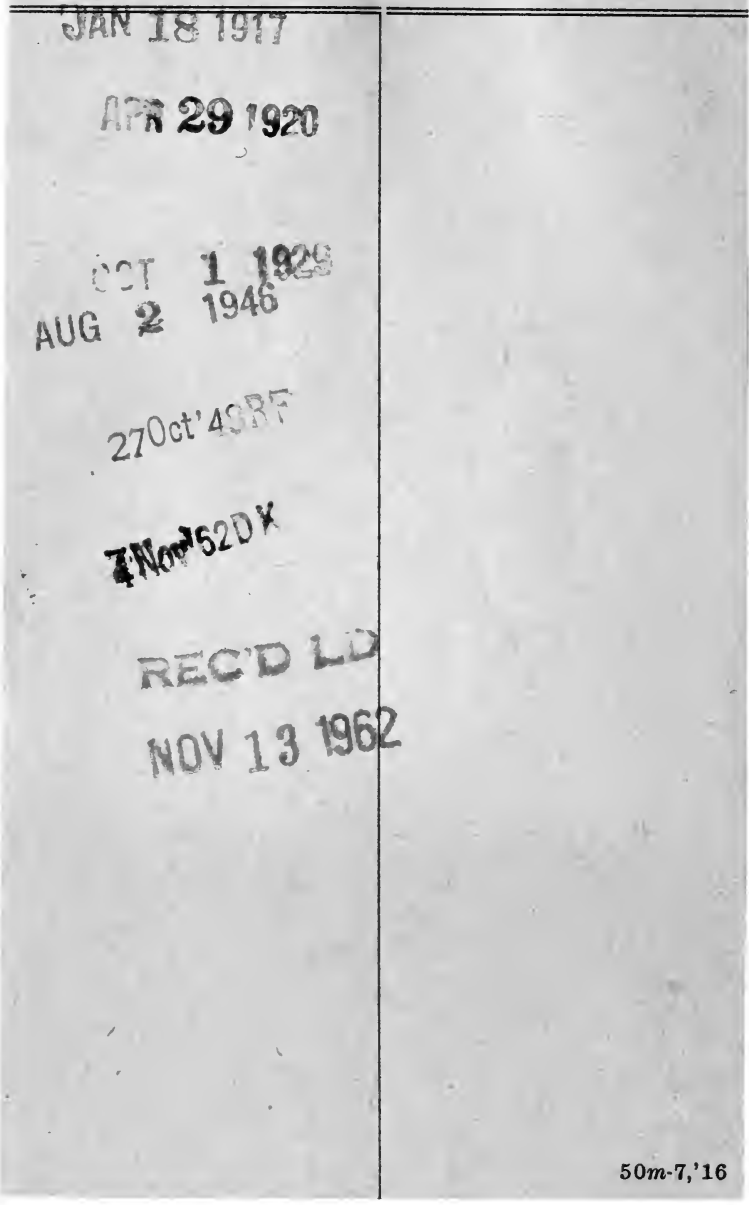




\section{YB 04824}

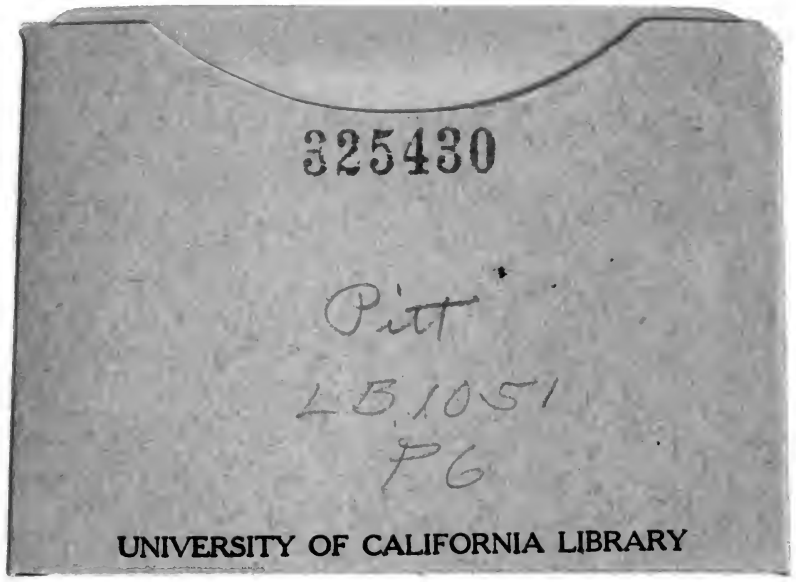




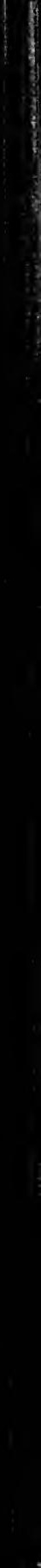

